\title{
Designing safe and stable tailings dam structures with centrifuge modelling
}

\author{
E. De Souza \\ The Robert M. Buchan Department of Mining, \\ Queen's University, Canada
}

\begin{abstract}
The failure of a number of waste dumps and tailings dams over the last decade has directed public attention to the potential hazard and severe environmental and safety impact created by mine tailings disposal, and has brought concerns on the need for more appropriate design, construction and management of tailings impoundments. Although past engineering research efforts carried out within the mining industry have developed unique strategies that normally result in stable tailings dam conditions, the effective and economic design, construction and maintenance of safe mine tailings dams still constitute a major technical challenge to industry. As a manifested contribution to this continuing effort, this paper introduces the centrifuge as a modern and unique design and verification tool which provide viable solutions to the continuing effort towards the construction of safe mine tailings dams.
\end{abstract}

Keywords: tailings dams, waste dumps, centrifuge modelling, stability design.

\section{Introduction}

Tailings dam failures generally result in catastrophic ecological disasters. Failure of an embankment generally results in liquefaction of the unconsolidated tailings mass, which can flow many miles in the surroundings. Because of the potential hazard and severe environmental and safety impact created by mine tailings disposal, industry has taken leadership in developing extensive research towards improved tailings dam design and management techniques that address both the safety and the environmental issues of tailings disposal.

The mining industry is more and more expected to achieve high environmental performance in their operations, and high design standards are 
required by government and regulators. New technology and risk-based design solutions have emerged, thus facilitating effective environmental impact assessments of planned, operating or after-use tailings impoundments.

This paper introduces the centrifuge as an integral component of the design and verification process of mine tailings dams. A case study developed for an operating mine is provided to illustrate the effectiveness of the centrifuge as a modelling and design tool for a large tailings dam structure.

\section{Mine tailings dam engineering practices}

\subsection{Dam stability issues}

As larger mining operations have become predominant in the last decade, larger tailings impoundments, containing billions of tons of tailings, and higher dam structures, reaching more than 200 meters, have evolved; the ecological impacts of such impoundments are being increasingly scrutinized by the general public. Recent massive impoundment failures have imposed new challenges to industry to not only guarantee the integrity of such structures over the life of a project but to minimize any ecological impact associated with tailings disposal.

Studies of incidents have indicated that most accidents and failures of tailings dams occur in active tailings ponds (USCOLD [1]). According to USCOLD the causes of failure of upstream tailings dams, the type of dam structure most susceptible to failure, are, in decreasing importance: slope instability, earthquake, overtopping, seepage, foundation and structural. Some of the most recent serious incidents include Aberfan in Wales, Buffalo Creek in USA, Bafokeng in South Africa, Stava in Italy, Merriespruit in South Africa (Brinsden and Lewis [2]), El Cobre in Chile (Zeng et al. [3]), Omai in Guyana (Vick [4]), Los Frailes in Spain (Lindvall et al. [5], Spooner [6]), Baia Mare in Romania (Bandi [7]), Nandan County in China (UNECE [8]), Nova Lima in Brazil (IGAM [9]), San Marcelino in the Philippines (WISE Uranium Project [10]), Malvesi in France (CRIIRad [11]), Zhen'an County in China (UNECE [8]), and Karamken in Russia (WISE Uranium Project [10]). Detailed chronologies of major tailings dam failures are described by WISE Uranium Project [10] and ICOLD [12]. It is generally agreed that most accidents are the result of a combination of faults, omissions, oversights and inappropriate management actions and that although such events are difficult to predict, appropriate management intervention could normally prevent most of the failures (Brinsden and Lewis [2], Glos [13]).

\subsection{Environmental impacts associated with tailings dam failures}

Other than the possible heavy loss of life and economic losses, environmental damaging impacts associated with structural failures in dams include (UNEP [14]):

- damage or destruction of valuable habitats and ecosystems;

- release of effluent from an impoundment may contaminate surface water; 
- generation and release of acid mine drainage may occur;

- seepage of effluent throughout the base of the structure may contaminate groundwater;

- $\quad$ seepage may result in substantial mounding of the natural groundwater table and provoke soil salinity problems;

- dried tailings may be swept as dust by strong winds into neighbouring habitations or ecosystems;

- effluent in tailings impoundments may generate toxic gases that may poison birds attracted by water in dry regions;

- poorly designed and protected ancillary structures may trap or drown wildlife;

- landscape changes by major tailings impoundments may be unacceptable in areas of scientific or scenic significance.

Companies are now expected to have high quality standards to tailings dam construction and management. Any new mining project requires that extensive environmental impact studies, emergency preparedness studies, sustainable development studies, dam design risk assessment and reclamation programs be developed before site permitting and implementation.

\subsection{A review of tailings dam construction methods}

A number of arrangements are required to be developed when constructing a tailings disposal system (UNEP [14]):

- a system for the delivery of the tailings to the disposal site;

- embankments to confine the tailings within the site;

- an arrangement for diverting natural runoff around or through the impoundment;

- a system for the deposition of the tailings within the impoundment;

- a facility for the evacuation of excess supernatant water from the impoundment;

- a system of measures to protect the environment from pollution.

Tailings dams can be classified based on the construction method either as water retention dams or raised embankments (ICOLD [15]). Water retention dams are constructed to their full height prior to impoundment while raised embankments are constructed in stages throughout the life of impoundment. Raised embankments are further classified according to the direction in which the embankment crest moves in relation to the starter dam: upstream, downstream and centreline dams.

The following more detailed classification of dams, based on the construction material utilized, has been suggested by UNEP [14]:

- conventional dam embankment;

- staged conventional embankment;

- staged embankment with upstream impermeable zone;

- embankment with tailings impermeable zone;

- embankment with tailings in structural zone (upstream, downstream, centreline construction);

- upstream construction using beach or paddock (spigot disposal method, sub-aerial disposal method, paddock disposal method). 
Each method of construction has its inherited advantages and disadvantages. Water retention dams have a high initial cost while raised embankments have a distributed cost over the life of the project. The selection of the embankment type is a function of a number of factors including the characteristics and constraints of the site; earthquake considerations; the type of tailings; construction materials used; and cost considerations. The popular upstream raised embankment is the most susceptible to instability problems and appropriate design, construction and management practices must be carefully implemented.

A unique disposal system, referred to as the Thickened Tailings Disposal, has been developed to minimize the ecological problems associated with the operation of conventional tailings disposal systems (Robinsky [16]). It involves the process of thickening the tailings to a heavy slurry prior to disposal, thus creating a self-supporting deposit of tailings. Because the settling pond is eliminated, failure within the well consolidated tailings material would only result in local slump, without flow. It is also noted that the system can inhibit acid drainage. The fines in the slurry of the thickened tailings deposit promote high matric suction, thus maintaining the tailings containing sulphides in a saturated condition. Such saturated environment prevents the breakdown of sulphides into sulphuric acid which would otherwise dissolve other undesirable metallic elements that may contaminate the surrounding environment.

\subsection{A review of dam design and operation practices}

Van Niekerk and Viljoen [17] explored the geological management causes of tailing dam disasters and provide the following guidelines to prevent future disasters:

- The topography of the area where the tailings dam is built should be carefully considered. Depositional sites should be relatively flat without undulating topography and preferably not on sites of drainage channels.

- Weak foundations will negatively influence slope stability of dam walls.

- Ground conditions and drainage facilities around dams should be sufficient to handle flood episodes.

- Dams walls should not exceed an inclination of 36 degrees and should ideally be less than 26 degrees.

- Excessive rainfall on the tailings dam will cause sudden rise in the water levels of the pond, which could lead to overtopping and therefore, facilities should be created to handle excessive rainfall on top of the dams, including an adequate properly functioning penstock and sufficient freeboard around the dam perimeter.

- Coarse and fine layering of tailings should be avoided to ensure prevention of the formation of piping.

- Tailings dams should be monitored regularly in terms of their characteristics and behavior.

The design process for a tailings disposal area involves the following steps (Taylor and D'Appolonia [18]):

- area selection; 
- determination of environmental constraints;

- determination of subsurface conditions;

- determination of the layout limits of the disposal area;

- determination of embankment cross-sections;

- slurry retainage considerations;

- analytical considerations (stability, seepage);

- construction or operation considerations (equipment selection, haul road location, support facilities);

- cost considerations;

- environmental planning (reclamation, fugitive dust, abandonment).

The dam design process thus involve a complex optimization study involving geotechnical and engineering performance considerations and construction techniques integrated with site, environmental, operational and cost constraints.

The selection of the site for disposal is a crucial component of the dam design and planning process and involves consideration of a number of important factors (UNEP [14]):

- proximity to the plant: lower transportation costs;

- embankment recovery: select site with a large ratio of storage volume to embankment volume;

- topography: avoid site with very steep slopes;

- natural runoff: avoid site with a large catchment area;

- elevation: select site with elevation close to that of the plant;

- foundation conditions;

- potential mining sites: avoid sites likely to contain mineable resources;

- human presence: avoid populated centres and areas of human activity;

- visual intrusion: select sites hidden from public view;

- environmental sensitivity: avoid sites containing endangered species of flora or fauna;

- groundwater considerations: avoid sites which could result in excessive seepage from the impoundment into the groundwater;

- erosion: avoid sites prone to water or wind erosion.

The most commonly used methods for assessing dam structural stability include methods of limiting equilibrium analysis and stress-deformation analysis using numerical methods based on classical soil mechanics consolidation models. Such traditional design methods cannot properly describe the complex behaviour involving flow, settling and consolidation of tailings and may underestimate the structural performance of dams under different operational conditions. This could ultimately result in inappropriate designs where unstable structural conditions may arise during the operation of the tailings management project. Dynamic physical modelling is introduced in this paper as a modern design and verification tool which may provide viable solutions to the effective design of tailings dams. A combination of centrifuge and numerical modelling can form a powerful tool to enhance the design of safer and more economic dams. 
The application of administrative controls and of risk-based assessments has been proposed for preventing dam failures during their operation. Brinsden and Lewis [2] report a risk based approach in which the probabilities of all the faults that can progress to trigger failures are first estimated, and then are combined in a fault-tree analysis such that the probability of failure and associated losses can be determined and specific management actions to prevent faults developing can be established. Glos [13] proposes the use of a four-part program of administrative controls for use in decreasing the risks and costs associated with tailings disposal facilities. The four proposed controls include the development of operating manuals to define the design criteria and construction procedures; the execution of quarterly operational inspections; the assessment of the seismic, hydrological and operational risk of the tailings facilities; and the provision of continuing technical advice to the line manager with respect to the technical aspects of the dam. This program is intended to provide the operational manager with detailed information to ensure that operation of the tailings facility follows the designer's intent, thus preventing facility misoperation and resulting failure.

\section{The centrifuge as a tailings dam design tool}

\subsection{Principles of centrifuge modelling}

Centrifuge modelling is a technique for reduced-scale physical modelling of gravity dependent phenomena, such as mine backfill and tailings dam behaviour. Centrifuge modelling is based on the fundamental concept that gravitational mass forces can be simulated by centripetal mass forces applied by the acceleration of a scaled model. The stress levels acting within an N-scaled model accelerated at $\mathrm{N}$ times the earth's gravity field are analogous to those acting on the prototype. For centrifuge modelling to be valid, similitude must exist between the accelerated scaled model and the prototype. Conditions of similitude are assessed using scale laws and dimensionless numbers. Scale factors and dimensionless numbers have been well established by many researchers for a multitude of engineering problems (Arulanandam et al. [19], Schofield [20]).

Regardless of the type of application, the principles and design of scale model experiments are similar and have been well established. First, a geometricallysimilar model, scaled down at $1 / \mathrm{N}$, is formed with materials of identical properties as that of a prototype. The transformation of the prototype must ensure that the model will have the same relative position, proportions, values and structure. The model is, in essence, a small prototype. This transformation is followed by a dimensional analysis and the development of dimensionless numbers. Similitude between the prototype and the scale model is obtained when the same dimensionless numbers are obtained in the prototype and model. The scale model is then placed in the centrifuge strongbox and rotated at a desired angular velocity. A corresponding centripetal force acceleration is experienced by the model in flight, and this acceleration induces self-weight forces in the test material. Thus, if a $1 / \mathrm{N}$ scaled model is accelerated to $\mathrm{N}$ gravities, the inertial mass induced stresses at any point in the model will be identical to the 
gravitational mass induced stresses at any similar point in the prototype, providing that the boundary conditions are identical at all equivalent points. All stress-induced and stress-gradient induced events will, then, occur in the model as they would in the prototype, but model events depending on gradients will occur faster because the physical distances are reduced in the model. The model accelerated in the centrifuge thus experiences analogous behaviour (patterns of strain, deformation, distortion, arching, cracking, failure, etc.) as the prototype.

\subsection{Modelling mine tailings dams}

Modelling tailings dams is based on the fundamental concept that gravitational mass forces can be simulated by centripetal mass forces applied by the acceleration of a scaled model. If the model dam is built from the same material as the prototype at a scale $1 / \mathrm{N}$, and the centrifuge is run such that the centripetal acceleration acting in the model is $\mathrm{N}$ gravities, then the stress levels due to gravity at corresponding points in the prototype $(\sigma=\rho g z)$ and in the model $(\sigma=$ $\rho \mathrm{Ng}(\mathrm{z} / \mathrm{N})=\rho g z)$ will be identical. If model boundary conditions are made to correspond with the prototype, then the strain fields and hence deformations and behaviour will be similar. Modelling of dams using a centrifuge is particularly useful for cases involving three-dimensional problems and partly saturated conditions.

\subsection{The centrifuge testing facility}

A schematic of the Centrifuge Testing Facility is shown in Figure 1. The centrifuge is a $5.3 \mathrm{~m}$ diameter machine driven by a $50 \mathrm{~kW}$ hydraulic motor and speed control assembly. It is designed to rotate up to a maximum speed of 350 rpm and it is capable of exerting up to 330 gravities on typical models. It is rated at $30 \mathrm{~g}$-tonne, since it can accelerate a 0.1 tonne mass to 300 gravities. The main beam of the centrifuge is $5.19 \mathrm{~m}$ long, including strong boxes, and is fabricated from a $200 \mathrm{~mm}$ steel tube of $13 \mathrm{~mm}$ wall thickness. Swing strong boxes are available to house specific scaled models. These are attached to one end of the main beam by a $70 \mathrm{~mm}$ diameter steel pin. A counter-weight box is attached to the other end of the main beam by two $25 \mathrm{~mm}$ diameter steel pins. The beam rotates on a $76 \mathrm{~mm}$ diameter steel shaft which is powered by the $50 \mathrm{~kW}$ hydraulic motor. The speed is controlled by ramping mechanisms in the hydraulic power supply, and can be maintained at any level between 50 and 350 rpm. The centrifuge has a total of 12 slip rings and instrumented models are monitored via a high speed data acquisition system. An image processing system is also used for visualizing and digitizing the real time behaviour of models captured by a digital dynamic video monitoring system.

\section{A tailings dam stability design case study}

A study was performed to investigate the stability of embankments used for tailings impoundment in an operating mine, employing the downstream and upstream methods of construction. Loading can generate excess pore pressures 
followed by liquefaction of the tailings mass, changing it into a viscous fluid and producing a large pressure increase on the embankment which can induce failure.

The structure investigated was a tailings dam facility to be constructed by the upstream method with a total height of $100 \mathrm{~m}$. The stability analysis of the embankment under loading considered such factors as consolidation rate, drainage and pore pressures. Construction options, including the upstream and downstream methods were investigated.

For the centrifuge modeling study, scaled physical models were built to simulate prototype conditions consisting of the initial construction stages of the tailings dam, with two lifts to a total height of $20 \mathrm{~m}$. Figures 1 and 2 present the models scaled at 100 gravities.

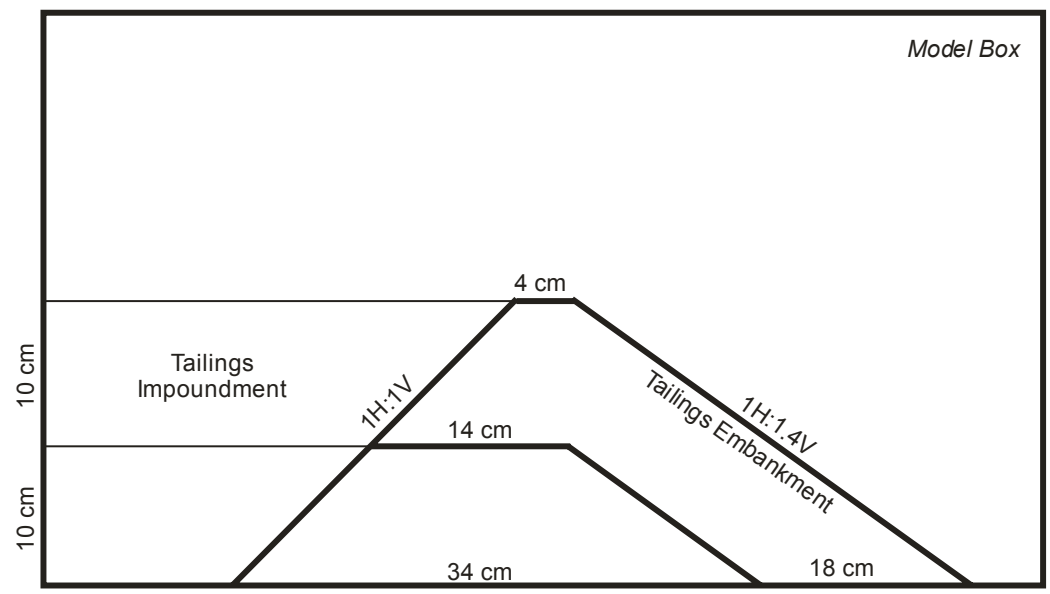

Figure 1: $\quad$ Profile of scaled model of downstream dam.

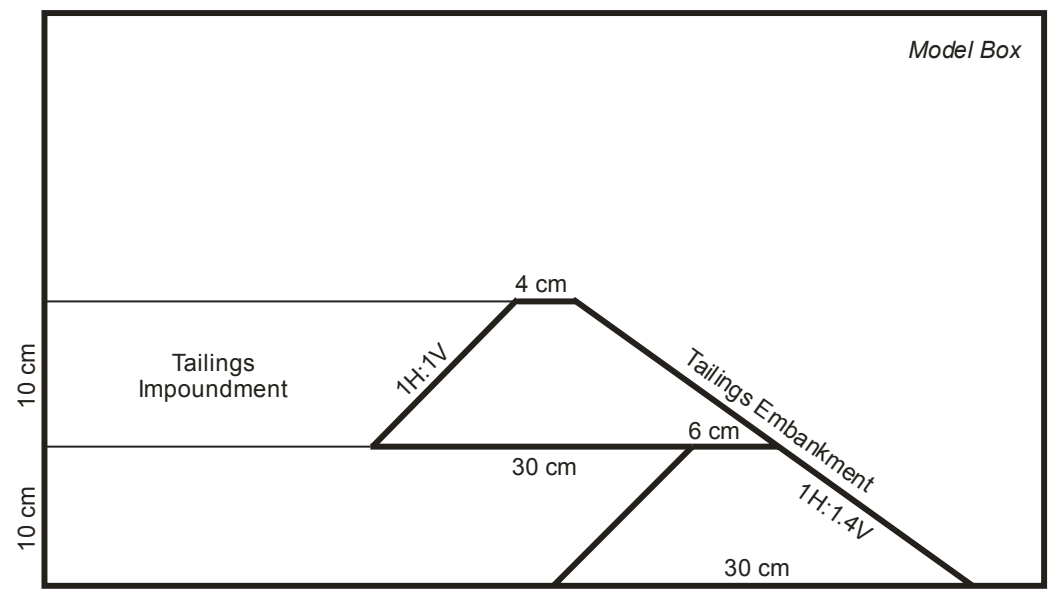

Figure 2: $\quad$ Profile of scaled model of upstream dam. 
All models were prepared using tailings from the mining operation. Treated form ply was used to construct the molds, which formed the scaled models. Prototype dams $30 \mathrm{~m}$ wide by $70 \mathrm{~m}$ long by $20 \mathrm{~m}$ high were represented by models $30 \mathrm{~cm}$ by $70 \mathrm{~cm}$ by $20 \mathrm{~cm}$ high, scaled at 100 gravities.

The model dams were built in two stages. The embankment dam was built under controlled conditions following the specified construction method and allowed to consolidate for a period of time. The exposed face of the dam was spray painted with white stripes to facilitate visual observation of deformation behaviour during flight. Figure 3 presents the stages of development of the downstream dam model. Unconsolidated tailings were then placed behind the dam retaining structure. The models were fitted with contact transducers to monitor the inception of failure. In preparation for testing, each model box was secured in the centrifuge swing strongbox. Figure 4 presents the dam in the centrifuge strongbox and ready for testing. The model was oriented to allow verification of the effect of the law of similitude where the boundary conditions and the effect of dam geometry and wall inclination were considered.
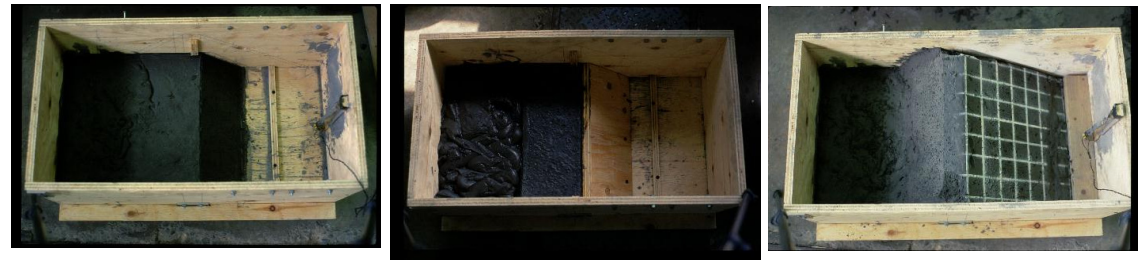

Figure 3: $\quad$ Stages of construction of a downstream dam model.

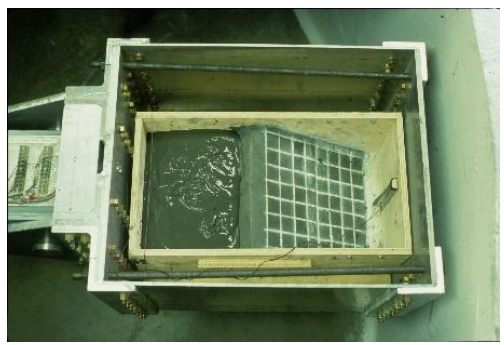

Figure 4: $\quad$ Model in centrifuge strongbox ready for testing.

During testing, the model was conditioned for 10-15 minutes at a centrifuge speed of $60 \mathrm{rpm}$ (producing accelerations of $10 \mathrm{~g}$ ). The centrifuge speed was then increased at a rate of approximately $2-3 \mathrm{rpm}$ per minute until either dam failure occurred or the design scale was achieved.

Figure 5 shows the profile of a downstream model before and after centrifuge simulation. Modelling has shown that a dam built by the downstream method has a much better dynamic stability than a similar dam built by the upstream method. 

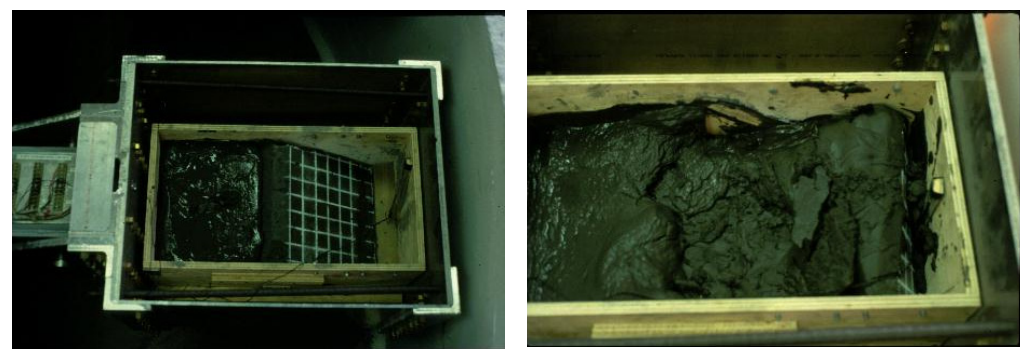

Figure 5: Profile of a downstream model before and after centrifuge simulation.

Observations of the mode of failure and material behavior indicated that pore pressures due to seepage may have caused mass instability and retrogression. This behavior was associated with the permeability properties of the embankment construction material.

Recommendations included construction of future embankments using the downstream method. Systematic control of the rate of construction was advised since high construction rates could pose a stability problem. The addition of toedrains was also recommended in order to improve slope stability. Monitoring of the phreatic surface on the downstream slope, which may lead to erosion or mass instability, was suggested.

\section{Conclusions}

Tailings dam failures generally result in devastating ecological disasters. This is because a conventional dam retains a massive amount of very loose unconsolidated tailings and large quantities of water and failure generally results in liquefaction of the unconsolidated tailings mass, which can flow many miles in the surroundings. Industry and regulators are aware of the need for improved tailings design and management techniques that address both the safety and the environmental issues of tailings disposal. This paper has demonstrated, through a case study, the effectiveness of centrifuge modelling in assessing the stability of tailings dam structures and proposes that the centrifuge be adopted as an integral component of the design and verification process of mine tailings dams.

\section{References}

[1] USCOLD. 1994. Tailings dam incidents.

[2] Brinsden, W.K. \& Lewis, P.A.P. 1996. Risk assessment in the design of tailings dams. Journal of the South African Institute of Mining and Metallurgy. 96(7):325.

[3] Zeng, X., Wu, J. \& Rohlf, R.A. 1998. Seismic stability of coal-waste tailings dams. Geotechnical Earthquake Engineering and Soil Dynamics 
III. Proceedings of a Specialty Conference: 950-961. American Society of Civil Engineers.

[4] Vick, S.G. 1996. Failure of the Omai tailings dam. Geotechnical News. 14(3).

[5] Lindvall, M., Oliva, A. \& Erikson, N. 1999. The Aznalcollar tailings pond accident - environmental impact and recovery measures. CIM Calgary 99. 101st Annual General Meeting.

[6] Spooner, J. 1999. The tailings spill in southern Spain: sharing the experience. CIM Calgary 99. 101st Annual General Meeting.

[7] Bandi, G. 2004. Liability and Sanctions, Criminal Liability in Hungary. Environmental Crime in Europe. Rules of Sanctions. 129-144. Europa Law Publishing.

[8] UNECE 2007. Transboundary Accidental Water Pollution, Liability and Compensation: Challenges and Opportunities. UNECE Workshop.

[9] IGAM 2001. Environmental Assessment of Mining Activities in the Water Resources of the Upper Rio Das Vellhas. 20. Instituto Mineiro de Gestao das Aguas.

[10] WISE Uranium Project (2010). Chronology of major tailings dam failures. www.wise-uranum.org.

[11] CRIIRad (2004). Rapport environnemental, social et societal. COMURHEX Malvési. CRIIRAD 06-88 v2.

[12] ICOLD. 2001. Tailings Dams, Risk of Dangerous Occurrences. Lessons learnt from practical experiences. Bulletin 121. International Commission on Large Dams.

[13] Glos, G.H. 1999. Using administrative controls to reduce tailings-dam risk. Mining Engineering. 55(9): 31-33.

[14] United Nations Environment Programme, UNEP. 1996. A guide to tailings dams and impoundments: design, construction and rehabilitation. Bulletin 106.

[15] International Commission on Large Dams, ICOLD. 1982. Manual on tailings dams and dumps. Bulletin no. 45.

[16] Robinsky, E.I. 1999. Tailings dam failures need not be disasters - the thickened tailings disposal (TTD) system. CIM Bulletin. 92(1028): 140142.

[17] Van Niekerk, H.J. and Viljoen, M.J. 2005. Causes and consequences of the Merriespruit and other tailings-dam failures. Land degradation and development 16, 201-212.

[18] Taylor, M.J. \& D’Appolonia, E. 1977. Integrated solutions to tailings disposal. Proceedings of the Conference on Geotechnical Practice for Disposal of Solid Waste Materials: 301-326. ASCE.

[19] Arunalandam, K., Thompson, P.Y., Kutter, B.L., Meegoda, N.J., Muraleetharan, K.K. \& Yogachandran, C. 1988. Centrifuge modeling of transport processes for pollutants in soil. ASCE Journal of Geotechnical Engineering. 114(2): 185-205.

[20] Schofield, A.N. 1980. Cambridge geotechnical centrifuge operations. 20th Rankine Lecture. Geotechnique. 30(3): 227-268. 